\title{
Piet Mondrian, early Neo-Plastic compositions, and six principles of Neo-Plasticism
}

\author{
Ali Fallahzadeh ${ }^{1} \&$ Ghulam-Sarwar Yousof ${ }^{2}$ \\ ${ }^{1}$ Visual Art Department, Cultural Center, 50603 Kuala Lumpur, University of Malaya, \\ Malaysia.ORCID: 000o-0002-0414-8702.Email: alfall2001@yahoo.com \\ ${ }^{2}$ (Corresponding author) Visual Art Department, Cultural Center, 50603 Kuala Lumpur, \\ University of Malaya, Malaysia. ORCID: oooo-0oo3-3567-6812 Email: \\ gsyousof@hotmail.com
}

\begin{abstract}
In spite of the prominent role of Piet Mondrian (1872-1944) as a pure abstract painter and writer of his theories who developed the abstract art into what he called Neo-Plasticism, little has been written about him compared to other painters such as Picasso and Matisse. Examining the past and recent literature published about Mondrian, some scholars examined the aesthetic evolution of Mondrian's vision toward his Neo-Plastic art and theory within a historical context by depending on the influences he received from circle of thinkers, artists, and friends during his life. While other scholars analyzed the components of NeoPlastic theory through formal tenets of De Stijl or a metaphysical lens through premises of western philosophies such as Theosophy, Hegel, and Platonism. Nevertheless, despite the emphasis of the majority of scholars on close relation between Mondrian's paintings and writings, researchers showed little tendency to examine the development of core formal theories of Neo-Plasticism through a parallel analysis of his Neo-Plastic paintings and his theoretical writings. Therefore, in this paper I aim to examine Mondrian's early artistic ideas, through a coinciding analysis of his 1919-1920 paintings and his 1919-1923 theoretical essays. In this article, I have considered six principles of Neo-Plasticism published in 1926 by Mondrian, as my main point of departure. The main objective of this paper is to reveal the degrees of Mondrian's awareness toward his refined, crystalized, aesthetic principles - he wrote in 1926 - by examining his early Neo-Plastic 1919-1920 compositions and his 1919-1923 theoretical essays. By conducting a contextindependent research on Mondrian's paintings and writings, I aim to propose a novel perspective looking through the very core theory of Neo-Plasticism and to motivate more scholars to examine Mondrian's NeoPlastic paintings and writings as integrated body of his Neo-Plasticism.
\end{abstract}

Keywords: Piet Mondrian, Neo-Plastic art, Neo-Plasticism, Six principles of Neo-Plasticism, Equilibrium, Rhythm.

\section{Introduction}

Considering the outstanding artistic career of Piet Mondrian (1872-1944) in the history of modern art for the development of the pure abstract art into what he called Neo-Plasticism, scholars have shown scant attention to the analysis of the development of core theory of Neo-Plasticism

(C) AesthetixMS 2019. This Open Access article is published under a Creative Commons Attribution Non-Commercial 4.0 International License (http://creativecommons.org/licenses/by-nc/4.o/), which permits non-commercial re-use, distribution, and reproduction in any medium, provided the original work is properly cited. For citation use the DOI. For commercial re-use, please contact editor@rupkatha.com. 
visualized and explained in Mondrian's Neo-Plastic paintings and his theoretical writings. In spite of emphasize of scholars on close relation between his theoretical writings and his paintings, these two has not yet used, as an integrated body of Neo-Plastic art, to explicate the components of this theory and more importantly to investigate the development and refinement of Neo-Plastic theory. The previous scholars has either focused on the formal analysis of Neo-Plastic paintings in absence of Mondrian's theoretical writings, or they have examined the components of NeoPlasticism based on the premises of De Stijl, Theosophy, Hegelian ideas, Platonism, and so on. Although, all the previous contextual approaches of the scholars significantly contributed to understanding of theory of Neo-Plasticism, particularly the philosophical and humanistic aspects of this theory, I, similar to Blotkamp, believe that the pictorial development of Neo-Plastic paintings should be analyzed in relation to Mondrian's theoretical writing. Indeed, in the earlier publications, the scholars mainly examined Mondrian's art and life within different historical and humanistic contexts. I argue that by excluding such contextual approaches and focusing on what Mondrian painted and wrote in different periods of Neo-Plasticism, we are able to come to a clear understanding of his development of formal theory, particularly his core six principles of NeoPlasticism, in different periods of Neo-Plasticism. Therefore, in this paper I aim to examine the early aesthetic evolution of Mondrian toward his art depicted in his early Neo-Plastic compositions (1919-1920) as well as in his theoretical essays written in the same period. For this study I consider six principles of Neo-Plasticism, Mondrian wrote in 1926, as crystalized version of his theoretical standpoint toward his Neo-Plastic art. My main objective is to discuss the degrees of awareness, maturity, of Mondrian toward these six principles, before writing them in 1926, in his early 1919-1920 Neo-Plastic compositions and writings. In my analysis I confined myself to the evolution of Mondrian's thought in respect to the theories he used (as he mentioned in his 1926 six principles of Neo-Plasticism) to attain pure, universal, expression of harmony (equilibrium), and rhythm in his early Neo-Plastic compositions. Considering the widely acknowledged fact that Mondrian's writings are posterior product of his paintings, and not vice versa, in this study a wider ranges of Mondrian writings, those he wrote between 1919 and 1923 is used under study. The six principles of Neo-Plasticism used as theoretical ground in this study, excerpted from one of Mondrian's 1926 published essays, are as followed:

1. The plastic means must be the rectangular plane or prism in primary colors (red, blue, and yellow) and in noncolor (white, black, and gray). In architecture, empty space can be counted as noncolor, denaturalized material as color.

2. Equivalence in the dimension and color of the plastic means is necessary. Although varying in dimension and color, the plastic means will nevertheless have an equal value. Generally, equilibrium implies a large area of noncolor or empty space opposed to a comparatively small area of color or material.

3. Just as dual opposition is required in the plastic means, it is also required in the composition.

4. Constant equilibrium is achieved by the relationship of position and is expressed by the straight line (boundary of the pure plastic means) in its principal, perpendicular opposition.

5. Equilibrium that neutralizes and annihilates the plastic means is achieved through the relationships of proportion in which they are placed and which create vital rhythm.

6. Naturalistic repetition, symmetry, must be excluded.

(Mondrian, 1926, p. 209) 


\section{An overview on aesthetic evolution of Mondrian toward his art (1887-1919)}

Mondrian was born in Holland in $\mathbf{1 8 7 2}$ when painters in Europe, particularly in Holland, were widely influenced by the Impressionist and post-Impressionist styles of painters such as Cezanne, Monet, and Van Gogh. Mondrian initially received drawing lessons and religious teachings of Calvinism from his father. His uncle Frits Mondrian (1853-1932) further advanced Piet Mondrian's artistic skills in landscape style of the Dutch Hague school of Impressionism. The majority of his artworks created between 1887 and 1907 are landscape artworks in variety of styles such as Impressionism, Post-Impressionism, and Symbolism. However, in the first decade of the $20^{\text {th }}$ century and concurrent with the emergence of many modern schools of painting in Europe, Mondrian's style changed to modernism. As such, his paintings executed between 1908 and 1911 are in modern styles such as Luminism, Pointillism and Fauvism.

Besides such stylistic influence of modern movements on Mondrian, one should not overlook his acquaintance with Theosophical teachings of early twentieth century thinkers such as Albert van den Briel and Edouard Schureas. As a result of contact with Theosophy, Mondrian's previous positivist and materialist vision shifted into a metaphysical and idealist vision and thereafter he sought beauty as truth and universal content in his paintings. His interest in mystical and spiritual teachings of Theosophy led him to join the Theosophical Society of the Netherlands in 1909. Through getting acquainted with the teachings of other Theosophists such as M.H.J Schoenmaekers and Rudolf Steiner in the second decade of the $20^{\text {th }}$ century, Mondrian's interest furthered toward mystical and cosmic teachings of Theosophy. Based on the theosophical thought, man evolves from the physical to the spiritual through cosmic laws of the universe. Such metaphysical standpoint of theosophists toward the notion of 'evolution' provoked Mondrian to paint a series of paintings based on Theosophical motifs between 1908 and 1912 (see figures 1 \& 2). The cosmic evolution from physical to spiritual was visualized by Mondrian in Evolution (figure 2) that shows the evolution of a physical nude woman on the right side to the icon of spiritual on the left.

Theosophy as a doctrine was established by Madame Blavatsky in 1875 in New York. Theosophists sought to reveal to mankind the very inner content of universal knowledge through metaphysical and antirational methods. Theosophists aimed to experience the universal truth in the universe, believing that such cosmic truth had remained veiled to man due to the dominancy of matter over spirit. Mondrian's interpretation from such cosmic teachings of Theosophy to reveal the spiritual, inner reality, emerged as a reductionist method in his style of painting. In this regard, after 1912 he steadily started to abstract, purify, all representational references to natural appearances (form) and colors. He came to this idea that the in painting the pure and universal content of beauty can only be expressed through balance (equilibrium) between the abstracted elements of painting (line, color, and plane) as dual oppositions. 

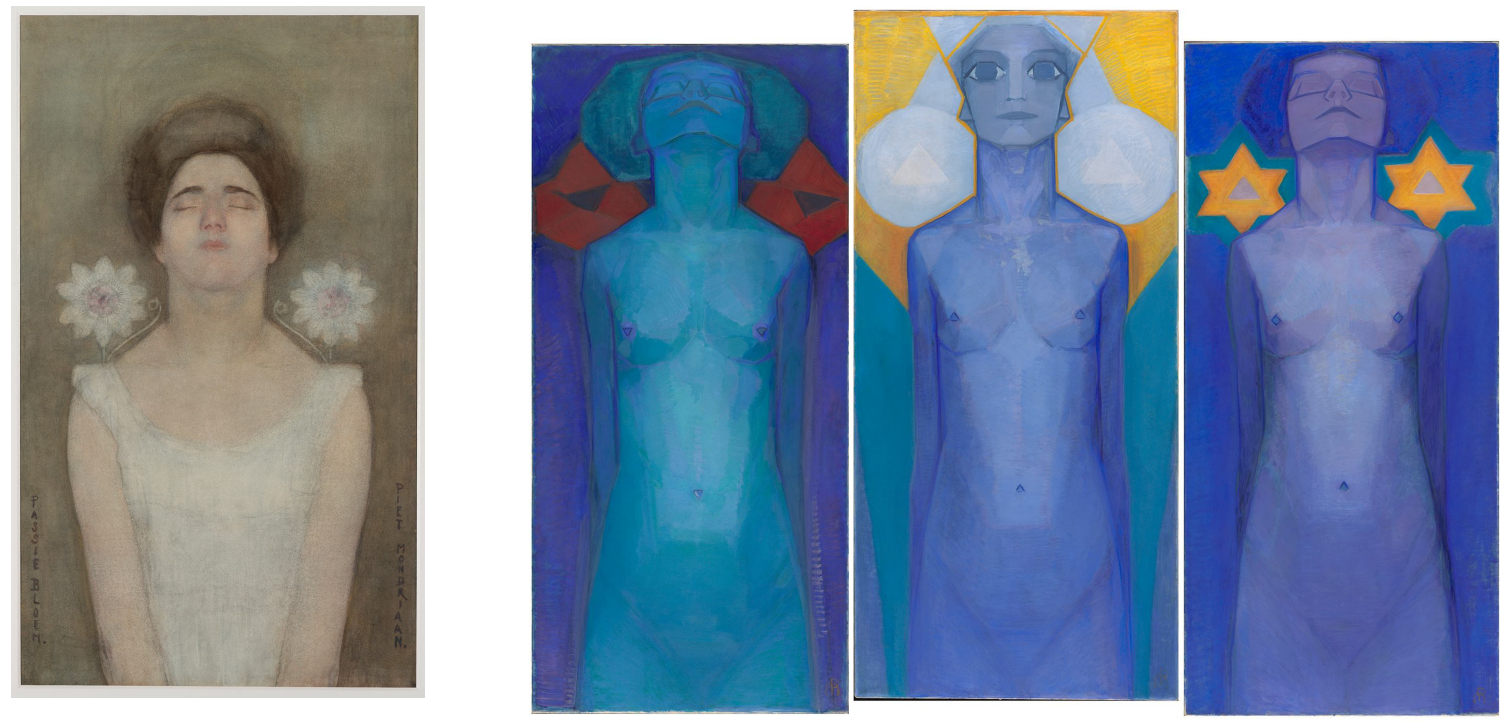

Figure 1: Piet Mondrian. Circa 1901-1908. Passion flower. Watercolor and black crayon on paper, 72.5 x $47.5 \mathrm{~cm}$. Reproduced with the permission of Gemeentemuseum, The Hague.
Figure 2: Piet Mondrian. 1911. Evolution. Oil on canvas, triptych, $178 \mathrm{x}$ $85,183 \times 87.5,178 \times 85 \mathrm{~cm}$. Reproduced with the permission of Gemeentemuseum, The Hague.

Besides the impacts of the teachings of Theosophy on Mondrian, modern tenets of Cubist artists, particularly Pablo Picasso and George Braque, was another seminal factor that further evoked Mondrian to omit the representational elements in his paintings. In 1911, Mondrian first came across the avant-garde discoveries of Cubist painters in an exhibition held in Amsterdam. He then, in 1912, moved from the Netherlands to Paris to get himself more familiar with Cubist works and other modern styles. Indeed, Mondrian's two-year stay in Paris and his close contact with artistic circle of Cubist artists was a godsend gift for him to actually think about other nonrepresentational methods to depict the form in space. The impact from Analytical Cubism of Picasso and Braque is very palpable in oval shape 1912-1914 Cubists paintings of Mondrian (see figures $3 \& 4$ ). It is noteworthy that Mondrian never delved into Cubism and unlike many of his fellow artists gradually, after 1914, stopped to paint in manner of Cubist artists. He soon found out that the modern premises of Cubism, more or less bounded to representation of particular forms, could not help him to express the universal, pure, beauty as truth in his paintings. In 1914, due to the upcoming news of World War I and his father's sickness, he had to return to the Netherlands. Mondrian, contrary to his interest, had to stay in Netherlands until summer 1919. Years 1914-1919 for Mondrian was a golden period to contemplate on what he had learned in Paris from Cubist artists. It was during this time that he steadily developed and perfected the heritage of Cubist artists into a pure abstract style which after 1920 he branded it Neo-Plasticism. 


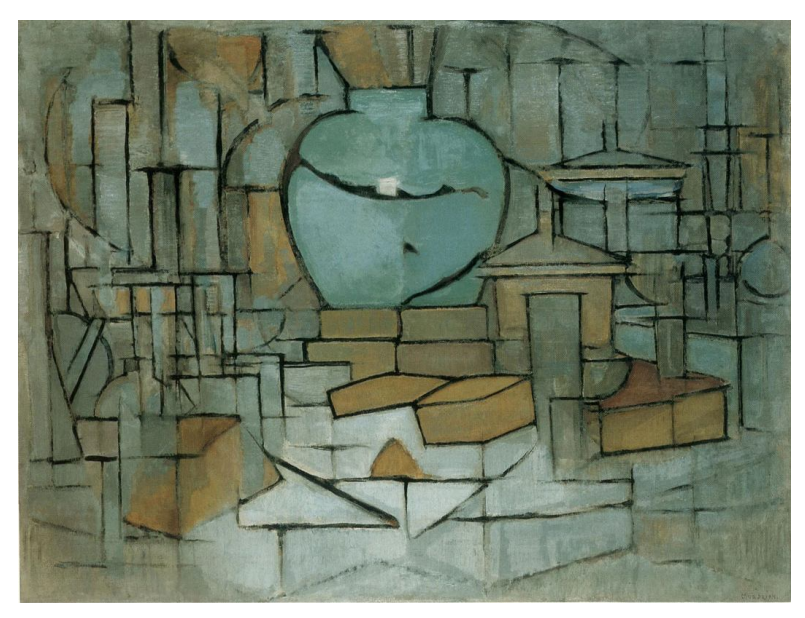

Figure 3: Piet Mondrian. 1912. Still life with gingerpot 2. Oil on canvas, $91.5 \times 120 \mathrm{~cm}$. Reproduced with the permission of Gemeentemuseum, The Hague.

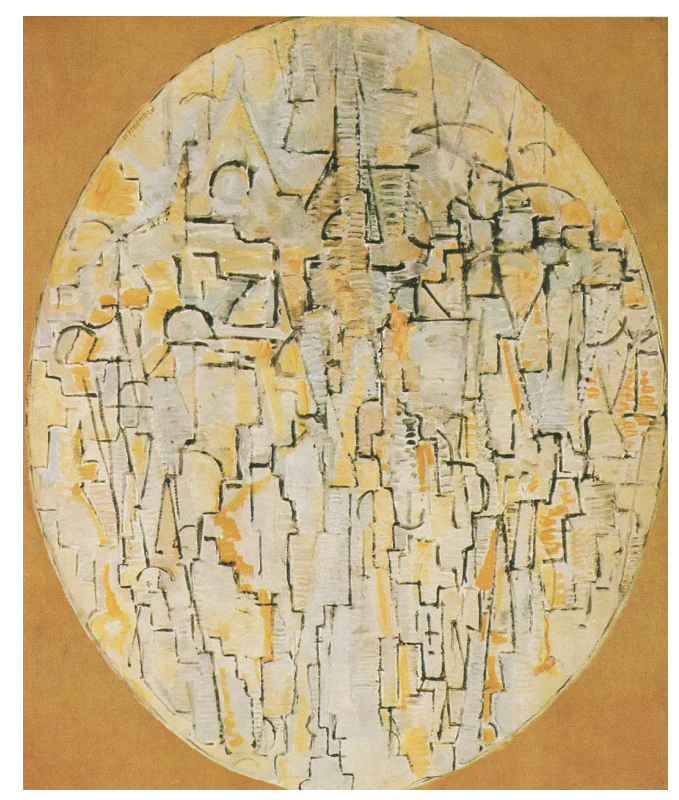

Figure 4: Piet Mondrian. 1913. Oval Composition (Trees). Oil on canvas, 72.5 x $47.5 \mathrm{~cm}$. Stedelijk Museum, Amsterdam.

After 1914, Mondrian's theoretical vision was further expanded by Hegel's philosophy through contact with the Dutch philosopher Bolland in Laren, a small village near to Amsterdam. Mondrian's interpretation of dialectics of Hegel was his theory of dual oppositions which he later in 1926 wrote it in his third principle of Neo-Plasticism as well. He, similar to Hegel, came to this idea that everything exist in relation to its opposite. As such, he defined such dual contraries as intensified, abstracted, opposing elements of paintings in his art. In this regard, he gradually abolished all curved and oblique lines in his compositions ${ }^{i}$ and replaced them with straight lines at right angle. He found that vertical and horizontal lines are in their utmost degree of opposition in respect to each other. As such, when we compare his 1913-1914 compositions to those created after 1915 we realize that in the latter compositions we rarely find curved and oblique lines. In compositions created between 1915 and 1917, he used frequent short crossings of vertical and horizontal lines that are congregated within an oval shape which are reminiscent to oval format of Cubist works of Braque. These compositions, commonly called plus-minus works of Mondrian (see figures $5 \& 6$ ), are indeed abstract interpretations of motifs such as church facades, piers and oceans, starry skies and seas. 


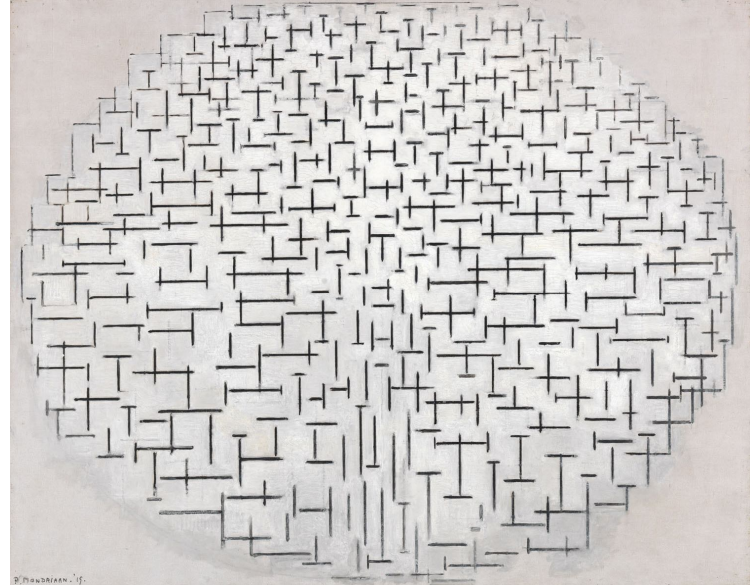

Figure 5: Piet Mondrian. 1915. Composition 10 in black and white. Oil on Canvas. 85.8 x $108.4 \mathrm{~cm}$. Reproduced with the permission of (C) Collection Kröller-Müller Museum, Otterlo, the Netherlands.

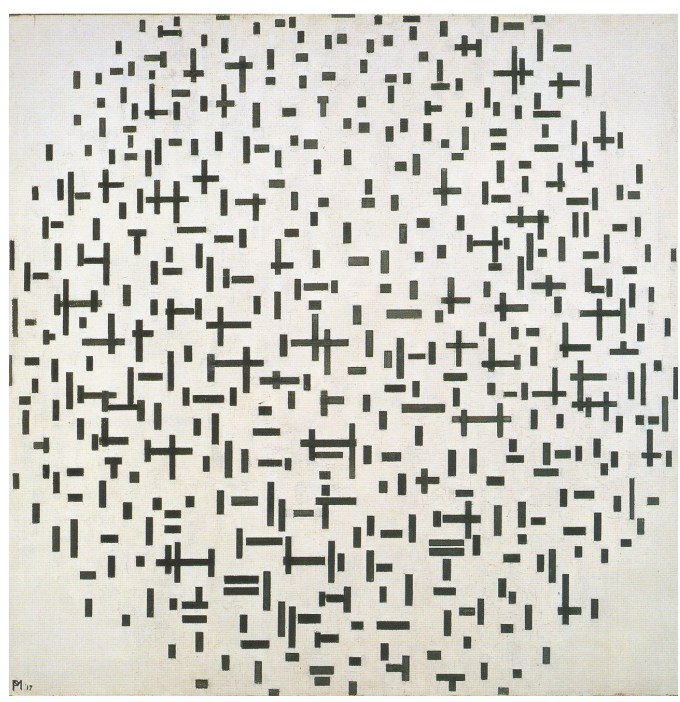

Figure 6: Piet Mondrian. 1916-1917. Composition in line, second state. Oil on Canvas. 108 x $108 \mathrm{~cm}$. Reproduced with the permission of (C) Collection Kröller-Müller Museum, Otterlo, the Netherlands.

After 1917, and in continuation of his artistic experimentations, Mondrian painted series of new works. In these paintings, he depicted hard-edge color planes of primary colors that are tinted with white. The planes of color are distributed randomly in the white surface of these composition. In later 1917 compositions, the color planes were arranged more evenly in rows and columns (see figures 7). In the absence of lines, these color planes seem floating in white surface (background) of the composition. As a result the color planes, as foreground, and white surface of the canvas, as background, are not in perceived in one flat layer. Mondrian who was aware about such inconsistency, in 1918 (see figure 8) added the element of line to further consolidate the color planes on the surface of the composition. Using lines to delimit the color planes and to abolish the contrast between ground and figure was indeed an efficient tactic Mondrian found after 1918 to attain purer unity and equilibrium. He further experimented on using the grid lines to determine the color planes in his last two 1918-1919 diamond works (see figure 9), and particularly in his two so-called 1919 Checkerboards (see figure 10). Indeed, Mondrian's last experimentations in Holland, before he moved to Paris in June 1919, on his two Checkerboards were seminal steps forward and aided Mondrian to propose his mature Neo-Plastic style after 1920. 


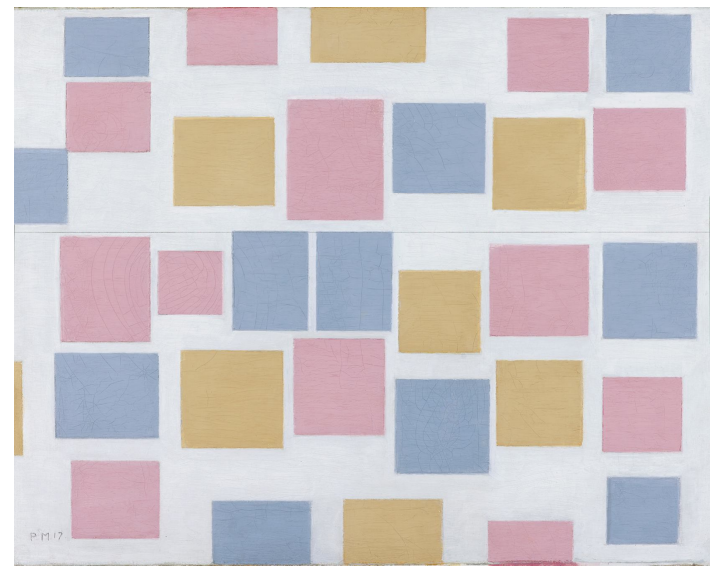

Figure 7: Piet Mondrian. 1917. Composition III with Color Planes. Oil on canvas. $187 / 8 \times 24$ inch. Reproduced with the permission of Gemeentemuseum, The Hague.

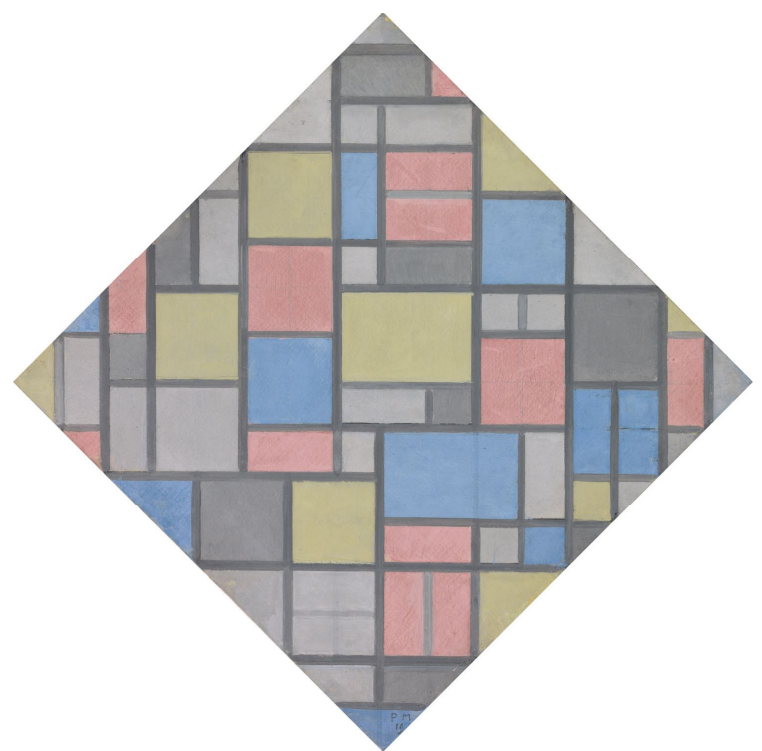

Figure 9: Piet Mondrian. 1919. Composition with grid 6: lozenge, composition with colours. Oil on canvas. $49 \mathrm{x}$ $49 \mathrm{~cm}$. Reproduced with the permission of (c) Collection Kröller-Müller Museum, Otterlo, the Netherlands.

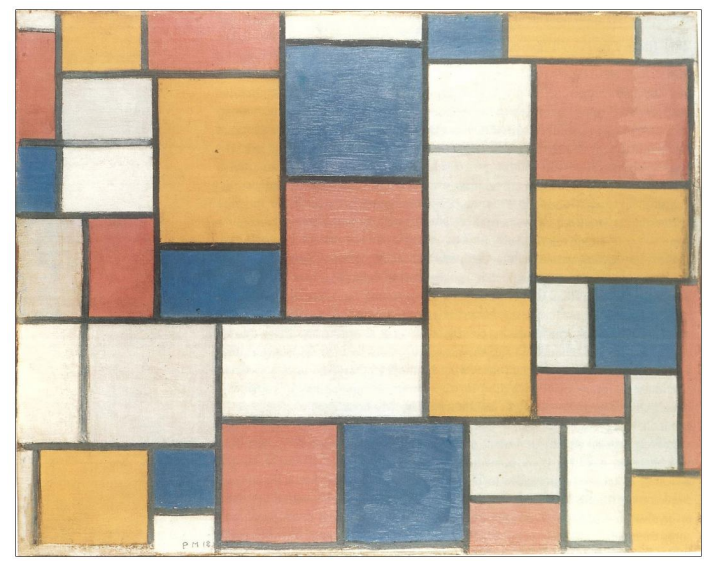

Figure 8: Piet Mondrian. 1918. Composition with Colour Planes and Grey Lines. 1918. Oil on canvas, 49 x $60.4 \mathrm{~cm}$. Max Bill collection, Zumikon, Switzerland.

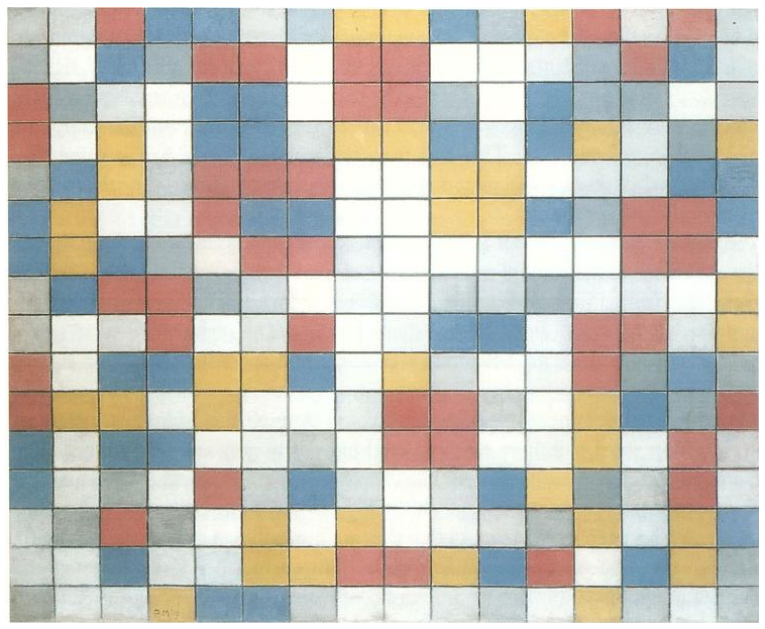

Figure 10: Piet Mondrian. 1919. Checkerboard, Light Colors. Oil on canvas. 86 x $106 \mathrm{~cm}$. Reproduced with the permission of Haags, Gemeentemuseum, the Hague.

Overall, five years of non-stop artistic experimentation of Mondrian from 1914 to 1919 in the Netherlands was one of the most critical transitory periods which led him to annihilate all the subjective and naturalistic references in his compositions. During this period he introduced abstract substitutes for conventional elements of line, color, and form in his pure abstract art or what he called abstract-real, Neo-Plastic, art. Mondrian called these abstracted elements of painting 'plastic means'. He defined those abstracted elements, new plastics, as exact oppositions that are essential to express the beauty as universal and truth. As such compositions created after 1920 were called Neo-Plastic. The term Neo-Plastic roots in a compound Dutch term 'nieuwe beelding'. The first part 'nieuwe' means 'new' or 'neo' in English. While the second part 'beelding' 
roughly means 'forming', mass or volume, or anything depicts in space. Mondrian called such materiality and mass of form 'plastic'. Therefore, the whole term Neo-Plastic, or what Veen (2017b) translated as 'means of imaging, refers to the new rendition of an abstracted visual entity which is portrayed as intensified elements of painting: lines at right - perpendicular - angle, colors in primary hues (red, blue, yellow), noncolors (white, grey, black), and flat plane. Mondrian considered such intensified elements - i.e. plastic means, means of imaging, the first essential prerequisite to attain the unity and equilibrium in his Neo-Plastic compositions. With this succinct overview on development of Mondrian's naturalistic style into pure abstract art, we will further examine Mondrian's early theoretical standpoint regarding to his core theory, focusing on his six principles of Neo-Plasticism, through examination of his early 1919-1920 paintings and 19191923 writings.

\section{An overview on the six principles of Neo-Plasticism}

Before moving to the analysis of the Neo-Plastic theories, we need to shortly explain a few concepts and theories commonly used as core theories in the majority of the Neo-Plastic compositions. The first one which is also stated in the first principle of Neo-Plasticism is the definition of 'plastic means' as purified and intensified elements of painting. In the first principle, Mondrian defined his means of imaging as rectangular planes of color (red, blue, yellow) and noncolors (black, grey, white). He considered the triad of primary colors as purified spectrum of colors, intensified form, material, or what he called 'filled form', found in the nature. Whereas, he considered the triad of noncolors as a new representation of space in his Neo-Plastic paintings. The second pivotal rule regarding to Neo-Plasticism is dialectics of dual oppositions that is also found in the third principle of Neo-Plasticism. Dual oppositions are indeed plastic means in NeoPlastic artworks which are binary opposing elements. The vertical opposes horizontal lines, color planes oppose non-color planes, and so on. Besides the apparent oppositions between the plastic means, means of imaging, there is also 'relationships' between line-plane, plane-color, color-line, and so on. In theory of Neo-Plasticism, the 'oppositions' of plastic elements is equal to the term 'relationship': "[w]e express ourselves plastically through oppositions of line and color, and this opposition is relationship" (Mondrian, 1919-1920, p. 84). Above all, the plastic means as dual oppositions and their relationships are the key prerequisites to achieve the harmony (equilibrium) in Neo-Plastic compositions. According to Mondrian, unity and equilibrium between dual oppositions attains through neutralization or what Mondrian called 'equivalent relationships' between plastic means. For Mondrian, the 'equivalent relationship' is a new rendition of the traditional concept 'harmony' in his new art. The old concept of the harmony, in Mondrian's stance, is vague and subjective since it is the outcome of inexact relationships of curve, oblique, natural forms, and colors in figurative (old) art. In this regard, Mondrian stated:

This harmony of art is so totally different from natural harmony that (in the new plastic) we prefer to use the term equivalent relationship rather than "harmony." However, the word "equivalent" must not be taken to mean symmetrical. Equivalent relationship is plastically expressed by contraries, by neutralizing oppositions, which are not harmonious in the old sense. (Mondrian, 1920, p. 145)

The third rule is related to the new definition of Mondrian for concept 'equality' or sameness of his means of imaging which is also partially stated in the above quote. Mondrian in his second principle of Neo-Plasticism stated that the equivalence is not similarity in size, color, or form. That is to say the sameness of means of imaging is not a quantitative quality. In the second principle he defined such sameness as an 'equal value' of his means of imaging which as he 
described in his writings means an exact opposition of means of imaging that is best demonstrated between vertical and horizontal lines. He maintained that in the Neo-Plastic painting an objective and universal harmony, he called equilibrium or equivalent relationships, can be expressed through perpetual relationships and neutralization of dual oppositions (plastic means, means of imaging). Moreover, in the fourth and fifth principles of Neo-Plasticism, he further explained that such equilibrium is the result of relationships between positions of opposing lines at right angle as well as the relationship between dimension and proportion of the planes. Mondrian always considered relationships between lines at right angle as immutable, most exact and universal, compared to the mutable nature of relationships between demission and proportion of the planes. In the fifth principle he also indicated that rhythm in the NeoPlastic painting expressed through variant relationship between proportions (dimension) of the planes. Lastly, in the sixth principle he also reminded us that to express a pure and universal rhythm, symmetry and repetition should be excluded in Neo-Plastic painting. With these fundamental rules in mind, I will start to analyze Mondrian's early artistic theories through examination of his 1919-1920 paintings and 1919-1923 writings, prior writing his six principles of Neo-Plasticism.

\section{Neo-Plastic 1919-1920 compositions and six principles of Neo-Plasticism}

As it was discussed, Mondrian throughout his 1914-1919 experimentations finally found his intensified elements of painting, means of imaging: vertical and horizontal lines, primary colors, noncolors, and flat plane. After he returned to Paris in June 1919, he was ready to formulate rules to compose his means of imaging, plastic means, in harmony (equilibrium) in his compositions. The impediments he faced in the previous 1914-1916 plus-minus compositions such as depth of field of the short crossing straight lines (see figures 5 \& 6) and floating state of the color planes in the 1917 compositions (see figure 7), provoked him after 1918 to consistently use the straight lines in his post 1919 compositions to enclose and delimit the color planes. By using grid-like lines in the 1918 compositions (see figure 8) and especially in the Checkerboard with light colors (see figure 10), Mondrian succeeded to further unite the background, as white surface of composition, and foreground, as color planes. However, the modularity, symmetrical, repetitive patterns of lines, and impurity in hue of colors (see figures 9 \& 10) were the main obstacles for him to express a universal, pure, equilibrium and unity in these compositions. The initial solution to amend such unwanted problems was suggested in Composition with Colour Planes and Grey Lines (see figure 8) which should be considered as immature version of a Neo-Plastic composition. In continuation of his experimentations on using his lines at right angle to determine the color planes, after 1919 he started to slice the composition asymmetrically that resulted in creating unequal sized rectangular planes. The color planes on a flat plane henceforth considered as abstracted forms (filled space) and noncolors were counted as empty space. Such developments in arrangement of the plastic means are palpable in the first series of Neo-Plastic compositions executed between 1919 and 1920 as are shown in figures 11 to 14. 


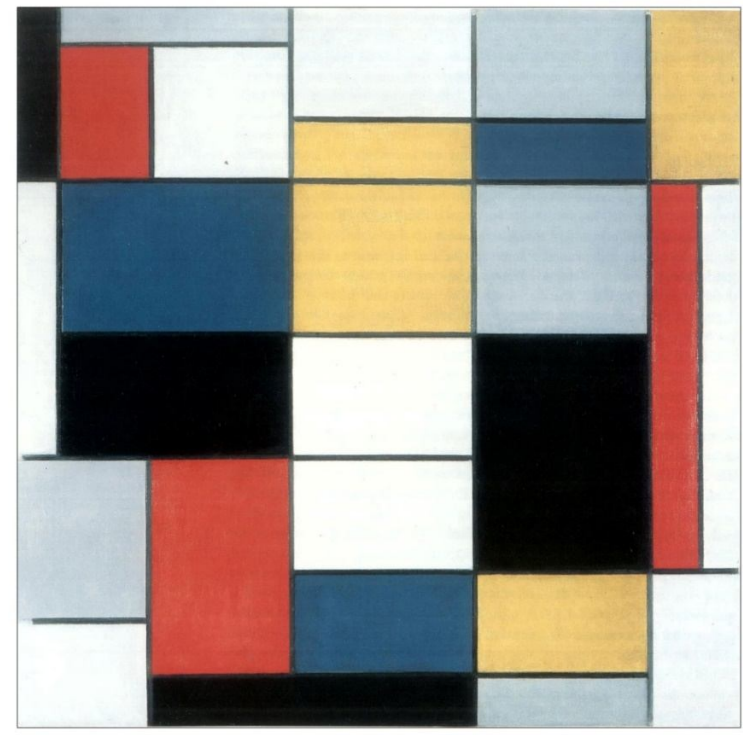

Figure 11: Piet Mondrian. 1919. Composition with Red, Yellow, Blue and Black. Oil on canvas. 90 x $91 \mathrm{~cm}$. Reproduced with the permission of Rome, National Gallery of Modern and Contemporary Art. By permission of Ministero dei Beni e delle Attività Culturali e del Turismo.

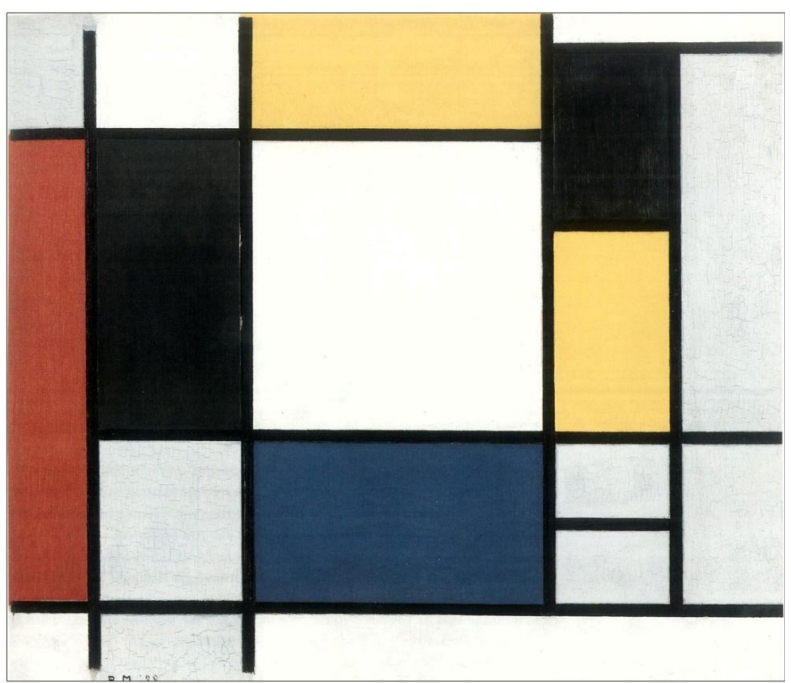

Figure 13: Piet Mondrian. 1920. Composition with Red, Yellow and Blue. Oil on canvas, 51.5 x $61 \mathrm{~cm}$. Stedelijk Museum, Amsterdam.

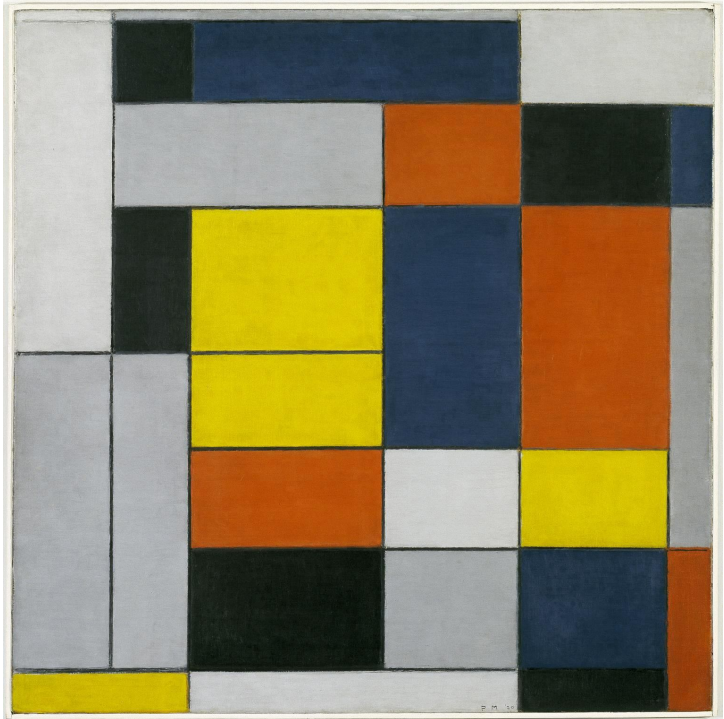

Figure 12: Piet Mondrian. 1920. No. VI / Composition No.Ila. 997 x $1003 \mathrm{~mm}$. Reproduced with the permission of (C) Tate Gallery London. CC-BY-NC-ND 3.0 (Unported)

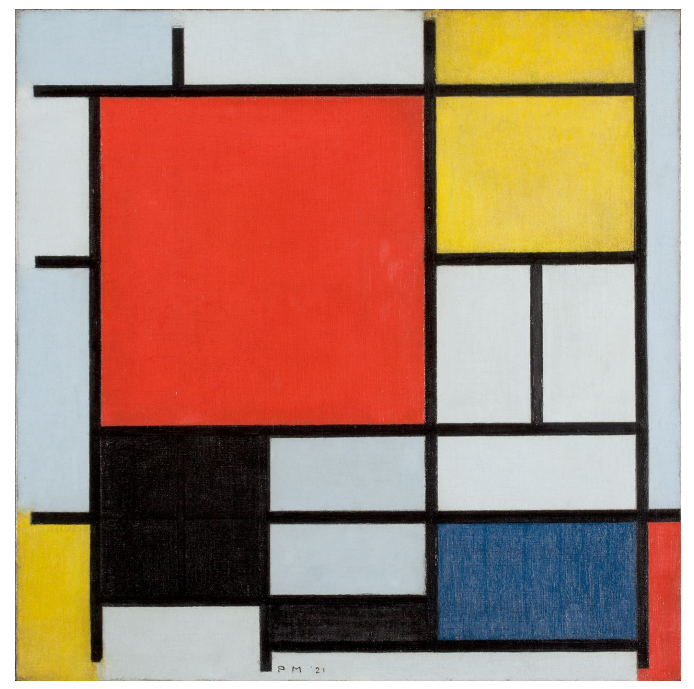

Figure 14: Piet Mondrian. 1920. Composition with Red Yellow, Blue and Black. Oil on canvas, 59.5 x $59.5 \mathrm{~cm}$. Reproduced with the permission of Gemeentemuseum, The Hague.

Starting our analysis with the means of imaging (first principle of Neo-Plasticism), we see that in the 1919 compositions and early 1920 compositions (see figures 11 \& 12), lines are grey and thin. While in later 1920 compositions, Mondrian gradually increased the thickness of his lines (see figure $13 \& 14$ ) in order to better determine the rectangularity as well as the proportionate ratios of his planes in respect the size of the composition. What is apparent in all four compositions is the incomplete extension of lines to the edges of the canvas. Moreover, primary 
colors in the latter two compositions (figures $13 \& 14$ ) are purer in hue compared to earlier ones (see figure 12). In Mondrian's vision the pure colors are intensified, abstracted version, colors found in nature: "all naturalistic color when intensified is pure, just as all line when intensified is straight, and all form when intensified is plane" (Mondrian, 1919-1920, p. 118). In fact, we surmise that Mondrian as early as 1919-1920 was already aware that his means of imaging are flat rectangular planes of color. When we look at the above 1919-1920 paintings we see that, regardless of some inconsistencies in the thickness and hues of lines in 1919 paintings (figures 11), Mondrian as early as 1919 used triad of primary colors and noncolors as his means of imaging. Interestingly, when we read Mondrian's essays he wrote in this period, we realize that it is not until 1921 when he indicated to the triad of black, grey, and white as 'noncolors'. Such precedence of practice to theory is indeed what distinguishes Mondrian from many of his fellow artists. For example in his 1919 essay Dialogue on the New Plastic he stated that: "[p]ainting has to be purely plastic, and in order to achieve this it must use plastic means that do not signify the individual. This also justifies the use of rectangular color planes" (Mondrian, 1919, p. 78). And after 1921 Mondrian started to talk about 'noncolors' as opposing triad of primary colors. For instance, in his 1921 essays The Manifestation of Neo-Plasticism in Music and the Italian Futurists' Bruiteurs he said: "[o]bjects and beings are thus reduced to a universal plastic means that 'expresses' them but does not presume to represent them. This new reality in painting is a composition of color and noncolor" (Mondrian, 1921, p. 150). Similarly, in his 1922 essay Neo-Plasticism: Its Realization in Music and in Future Theater he also stated: "[i]n Neo-Plastic painting the plastic means is determined color, the duality of color and noncolor" (Mondrian, 1922, p. 161). From these two statements, we realize that Mondrian after 1921 came to a mature understanding about his means of imaging as he later, in 1926, mentioned in his first principle of Neo-Plasticism. However, we found the closest statement to what he said in his first principle ${ }^{\mathrm{ii}}$ of Neo-Plasticism in his 1923 essay Neo-Plasticism as followed:

This plastic expression of planes is determined by the straight and is realized in pure primary colors (yellow, blue, and red) opposed to noncolor (white, black, and gray). [...] Neo-Plasticism expresses itself as a multiplicity of rectangular planes or rectangular prisms in color and noncolor. (Mondrian, 1923b, p. 176)

Therefore, we surmise that Mondrian after 1921 had in his mind a transparent idea for the characteristics of his means of imaging. Similarly, Mondrian in his 1919-1920 paintings, particularly his 1920 compositions (see figures 13 \& 14), used rectangular planes of color and noncolor as his essential elements of painting. Nonetheless, as we discussed, due to the incomplete extension of the lines to the edges of these paintings, the peripheral planes are not shown as perfect delimited rectangles. Moreover, the colors in the 1919 and early 1920 paintings (see figures 12 \& 13), are not as pure as the late 1920 paintings (see figures 14). Overall, we infer that during 1919-1920 Mondrian's artistic ideas regarding to his means of imaging was developing toward a maturity compared to what he later mentioned in his first principle of Neo-Plasticism in 1926.

Regarding to the concept 'equivalence' (second principle), when we look at the 1919-1920 paintings, we realize that Mondrian as early as 1919 had already found out that the equivalence of his means of imaging is not sameness in size or color of his means of imaging. In contrast to his diamond 1918-1919 paintings when his means of imaging were represented more or less as similar units, in his 1919-1920 compositions, he asymmetrically divided his compositions into unequal planes. In this regard, we see that except for a few planes in the 1919-1920 compositions which are similar in size, the planes are in harmony (equilibrium) through opposition of the dissimilar sized color and noncolor planes. Interestingly and concurrent with the creation of his 1919-1920 
compositions, Mondrian in his 1919-1920 essay stated that: "Equivalence does not mean uniformity or sameness, any more than it means quantitative equality" (Mondrian, 1919-1920, p. 97). When we compare this early statement of Mondrian with that of 1926 second principle ${ }^{\mathrm{iii}}$ of Neo-Plasticism, we find that Mondrian as early as 1919 had come to a mature understanding about his concept 'equivalence' of his means of imaging. He demonstrated and wrote in his 1919-1920 paintings and writings a true demonstration of what he later in 1926 stated about the equivalence between his means of imaging. That is to say, as early as 1919 the premises of the second principle, he wrote in 1926, had been in his mind.

Moving to the theory of dual oppositions (premises of the third principle of NeoPlasticism), when we look at the 1919-1920 compositions, we also realize that Mondrian used his lines and color and noncolor planes in exact opposition. Compared to the 1917-1919 compositions (see figures 7 to 10), in the 1919-1920 compositions the lines as well as color and noncolor planes are depicted in a more distinct opposition. Thick vertical lines opposed to the thick horizontal lines, bigger colored and noncolored planes opposed to smaller ones, and so on. The noticeable variation in dimension of color and non-color planes further enhanced the dual tension between plastic means which is essential to express relationships. As such the spectator sees the relationship between dual plastic contraries in the composition and not the plastic means as standalone entities. Concurrent with the creation of his 1919-1920 paintings, Mondrian in his 19191923 writings, emphasized on the importance of the oppositions to express the 'relationship' between means of imaging and in the composition. For example in his essay Natural Reality and Abstract Reality he said: "[t]o express plastically color and line means to establish opposition through color and line; and this opposition expresses plastic relationship. Relationship is what I have always sought, and that is what all painting seeks to express" (Mondrian, 1919, p. 76). Similarly, in the same essay we read that: "[w]hen we see something as a thing-in-itself, we separate it from the whole: opposition is lacking-we no longer see relationships but only color and form" (Mondrian, 1919-1920, p. 86). In the latter statement, Mondrian emphasized on his core theory of dual oppositions which he borrowed from Hegel's philosophy. He delineated that nothing exist as a standalone entity and everything exist in relation to its opposition. Mondrian in his 1920 essay Neo-Plasticism: The General Principle of Plastic Equivalence shed more light on the necessity for duality between means of imaging to express the relationships and thereby the equilibrium (harmony) in Neo-Plastic painting: "[t]he essential is that the principle of opposites rules the work as a whole as much in its composition as in the equilibrated relationship of its plastic means" (Mondrian, 1920, p. 141). Overall, we contend that Mondrian in both his early paintings and writings had already had a good understanding of his theory of dual oppositions which he later, in 1926, wrote it as his third principle ${ }^{\text {iv }}$ of Neo-Plasticism.

Regarding to the concept harmony or what Mondrian called 'equilibrium', we see that the equilibrium in his 1919-1920 compositions, particularly his 1920 compositions (see figures 13 \& 14), is expressed through relationships between lines at right angle as well as the variance of the dimension of dissimilar sized color and noncolor planes. By using thicker and more solid black hues for lines in the 1920 compositions, Mondrian succeeded to articulate a more dominant representation of the relationships between position of his intersecting lines. As it was discussed the relationship between position of lines is primary and substantial to attain the equilibrium in the composition. Whereas, the relationships between dimension and proportion of the planes are mutable, changeable, and so secondary. It is noteworthy that the relationship or position between lines at right angle is primary and a prerequisite to express the mutable relationships between dimension of the planes as Mondrian explained in his 1919-1920 essay: "[b]oth the relationships of color and the relationships of dimension are sustained by the relationship of position" (Mondrian, 1919-1920, p. 85). Indeed, without the existence of intersecting lines, there is no possibility to 
articulate the relationships between dimensions of the planes. For Mondrian, the relationship between lines at right angle is an essential condition to achieve the equilibrium (harmony) in the composition. In his 1922 essay he indicated to this matter: "[t]he rectangular position, the expression of the immutable, is the core of the Neo-Plastic plastic means. From this the power and equilibrium of the image derive" (Mondrian, 1922, p. 161). Mondrian asserted that the straight lines at right angle (as the perfect prototype of dual oppositions) neutralize, annihilate, their duality in the composition and the equilibrium is the result of such constant neutralization perpetual interplay between the vertical and horizontal - of the opposing lines. In this regard, in his 1923 essay Is Painting Inferior to Architecture? He called to his lines at right angle as 'selfannihilating' opposing elements: "[ $t$ ]he absolute is expressed in the straight. Painting and architecture in the new aesthetic are consequent realizations of composition of the straight in self-annihilating opposition, thus a multiple duality of the constant rectangular relationship" (Mondrian, 1923a, pp. 173-174). As such we understand that the equilibrium in Neo-Plastic paintings achieves through the 'naturalization' or 'annihilation' of duality of lines and planes of color and noncolor.

In his 1919-1923 writings, Mondrian also indicated to the method of attainment of the equilibrium which is indeed signals to what he later in 1926 wrote in his fourth and fifth principles of Neo-Plasticism. For example in his 1919-1920 essay Natural Reality and Abstract Reality he stated: "[t]he relationship of position cannot express equilibrium without equilibrated relationships of dimension" (Mondrian, 1919-1920, p. 85). In the same essay he also said: "equilibrium is expressed in a purely plastic way, through pure means: through the relationship of position and dimension of the straight" (Mondrian, 1919-1920, p. 105). When we compare the previous quotes with what Mondrian wrote in 1926 in the fourth and fifth principles ${ }^{\mathrm{v}}$ of Neo- $^{-}$ Plasticism, we contend that what Mondrian painted in his 1919-1920 compositions and what he wrote in his 1919-1923 essays are his emerging aesthetic ideas regarding the method and required conditions to express the equilibrium (harmony) in his Neo-Plastic theory. We also infer that Mondrian as early as 1919 was aware about the aesthetic conditions to express the equilibrium in his Neo-Plastic compositions. At this point, we argue that Mondrian in his 1919-1920 paintings, was not fully succeeded to express the equilibrium as he explained in his wirings. Due to the incomplete extension of the lines to the edges of these compositions, most palpable in figure 14, the relationship between dimension of the peripheral planes and those fully-enclosed central planes is not evenly and actively represented. That is to say, the relationship between dimensions of the central planes is represented more dominant and dynamic compared to those peripheral planes. Overall, in these 1919-1920 compositions, we realize some degree of immaturity in Mondrian's practice of what he wrote as theories regarding the aesthetic conditions for expressing the equilibrium.

Moving to concept rhythm (content of the fifth principle), we see that the rhythm in the 1919-1920 compositions more or less attained in line with what Mondrian in 1926 explained in his fifth principle of Neo-Plasticism. Looking at the four above 1919-1920 compositions, we find that the variety in size and dimension of the planes is the main source for creation of the rhythm. In the 1920 compositions (see figures 13 \& 14), due to the thickness of lines and asymmetrical division of the canvas, rhythm expressed more dynamic and vibrant compared to those 1919 compositions. In short, we realize that the rhythm in these compositions expressed through variant relationship between dimensions of the planes. However, similar to what we discussed in relation to the expression of the equilibrium, we assert that due to the incomplete extension of the lines, the peripheral planes (in particular in figure 14) are not actively in relationship with the central enclosed planes. As such the rhythm could not be expressed as 'vital' and dynamic as Mondrian mentioned in his fifth principle of Neo-Plasticism. Mondrian in his 1919-1923 writings also talked 
about rhythm. As early as 1919, in his 1919-1920 essay, Natural Reality and Abstract Reality, he explained the way rhythm expressed in Neo-Plastic paintings: "[i]n the New Plastic, rhythm, even though interiorized, continues to exist; it is, moreover, varied through the inequality of the relationships of dimension by which the relationship of position, the primordial relationship, is expressed" (Mondrian 1919-1920, p. 91). Mondrian in his post-1919 writings started to talk about two kinds of rhythm: natural rhythm and inward rhythm. As he explained, natural rhythm is the result of repetition of particular - naturalistic - forms. Whereas, the inward rhythm, related to Neo-Plastic (new art in general term) painting, achieves through the multiplicity, plurality, of abstracted, intensified, form. Mondrian considered the rhythm as a relative and dynamic expression in the composition which relativizes the absolute, immutable, relationships between lines at right angle. When we read the previous statements, we find that what he wrote in his early writings regarding to the expression of the rhythm are indeed signals to what he later stated in his fifth principles of Neo-Plasticism. We surmise that Mondrian as early as 1919-1920 had come to maturity regarding the aesthetic conditions and method to express the rhythm in his early Neo-Plastic paintings. In the first place, he indicated that rhythm is expressed through mutable relationship between dimensions of the planes (premises of the fifth principle). Secondly, he said that the relationship between dimensions of the planes directly depends on the primary relationship between position of the lines (content of the fourth and fifth principles). Overall, we infer that, during 1919-1920 Mondrian already arrived to a refined theoretical standpoint regarding his new concept of rhythm in his Neo-Plastic art. Nevertheless, as we discussed he had not yet fully demonstrated in his 1919-1920 paintings what he had theorized in his 1919-1920 writings about his conception of new, inward, rhythm.

Lastly and in respect to the sixth principle ${ }^{\mathrm{vi}}$ of Neo-Plasticism, we realize that Mondrian as early as 1919-1920 tried to exclude the symmetry and repetition in his paintings to express harmony (equilibrium). Although, in some cases in his 1919-1920 paintings some planes are arranged symmetrically in respect to each other (such as red and yellow planes in the lower left side in figure 12), in other cases, we see that planes are not repeated or arranged symmetrically. Concurrent with the creation of these paintings, Mondrian also emphasized that the symmetrical and repetitive rhythm of elements of painting should be avoided to express the equilibrium in Neo-Plastic painting. As he expounded, in Neo-Plastic painting the 'new harmony', or what he called equilibrium, could not be expressed through old and traditional rules of harmony: symmetry and repetition. In Neo-Plastic painting, the equilibrium attains through 'relationship' between intensified elements of painting (means of imaging, plastic means) and not repetitive pattern of forms. In his 1919-1920 essay Natural Reality and Abstract Reality he delineated this matter:

Naturalistic harmony, the old harmony, is not plastically expressed according to the concept of pure equilibrated relationship. It is expressed as relative equilibrium. It remains dominated by the "repetition" characteristic of nature: it expresses opposition but not the continuous annihilation of the one and the other. That is why the New Plastic is precisely against the old harmony. (Mondrian 1919-1920, p. 114)

As Mondrian stated in the above quote, the old harmony which is the harmony of the representational, figurative, painting is attained by using repetition and symmetry. However, in Neo-Plastic painting, the 'new harmony' achieves through balance between opposing plastic means, means of imaging. Mondrian in his writing in this period, called the harmony which is expressed through repetition and symmetrical arrangement of naturalistic forms as painting in the 'manner of nature'. Whereas he called the 'new harmony' which achieves through constant opposition of intensified form, color and line as painting in the 'manner of art'. In this regard, in 
his 1921 essay he said: "[i]t is through composition that the 'universal plastic means' must be expressed in continuously self-neutralizing plurality (and not by repetition in the manner of nature'). Without seeking symmetry 'in the manner of nature,' equilibrium must nevertheless predominate" (Mondrian, 1921, p. 154). As Mondrian indicated in this quote, in Neo-Plastic theory the plurality of the relationship between opposing plastic means is a new substitute for the traditional rules of harmony: symmetry and repetition. Indeed, in Neo-Plastic painting the 'equilibrated relationship' between means of imaging (plastic means) is a new rendition of old rules of harmony. Overall, we surmise that Mondrian both in his 1919-1920 paintings and 1919-1923 writings endorsed that repetition and symmetry should be avoided to express the harmony (equilibrium) in his Neo-Plastic compositions. Moreover, we contend that as early as 1919 he tried to exclude the symmetry and repetition on his paintings. As such, we understand that as early as 1919, he was fully aware about exclusion of symmetry and repletion in his paintings.

\section{Conclusion}

At the end, we surmise that looking through Mondrian's early Neo-Plastic paintings and writings within a context-independent approach helped us to reveal genuine and novel findings about his theoretical position of his early Neo-Plastic career. By analyzing Mondrian's early Neo-Plastic artworks and his texts in the same period, we found that in many cases what he painted and wrote were signals to his emerging aesthetic ideas to his mature theory of Neo-Plasticism which he later wrote within six principles in 1926. In regards to his elements of painting (plastic means, means of imaging), we saw that Mondrian as early as 1919 started to use rectangular planes of color and noncolor in his paintings. Similarly, in his post-1921 writings - similar to what he had later crystalized in his first principle of Neo-Plasticism - he defined his means of imaging as rectangular planes of color and noncolor. Nevertheless, we realized that Mondrian in his 1919-1920 paintings had not yet perfectly enclosed, delimited, the planes in the periphery of his compositions. Regarding his concept 'equivalence' of his means of imaging, we found that Mondrian in his 1919-1920 paintings, contrary to his former 1918-1919 paintings, stopped to divide his compositions through regular grid lines. As a result, the equilibrium in these compositions attained through opposition of unequal sized of the planes of color and noncolor. In his 1919-1923 writings, Mondrian, similar to what he later indicated in his 1926 second principle of NeoPlasticism, also further explained that equivalence is not a quantitative quality and it is an exact opposition of the means of imaging. Therefore, we inferred that Mondrian as early as 1919 was fully aware about a new conception of equivalence of his means of imaging which is not based on 'sameness' or similarity in size of the planes. In respect to the theory of dual oppositions, premises of the third principle of Neo-Plasticism, we also realized that Mondrian in his early paintings, particularly his 1920 paintings, as well as his writings emphasized on the essential need for the depiction of his means of imaging in exact opposition in respect to each other. We understood that the equilibrium in the 1919-1920 compositions attained, similar to what Mondrian had written in his fourth and fifth principles of Neo-Plasticism, through relationship between position of the lines and the relationship between dimensions of the planes. Similarly, we found out that the expression of the rhythm in the 1919-1920 compositions is primarily dependent to the variant relationship between dimensions of the planes. In his 1919-1923 writings, Mondrian also provided us with supplementary information about the method and aesthetic conditions to express the equilibrium and rhythm which were detailed explanations on what he had briefly crystalized in his 1926 principles of Neo-Plasticism. Lastly, we also inferred that Mondrian as early as 1919 had excluded symmetry and repetition, although not completely, in his paintings. Similarly, in his 1919-1923 early writings, similar to what he had written in his sixth principle of Neo-Plasticism in 
1926, he stressed that symmetry and repetition should be avoided in Neo-Plastic paintings since using these traditional rules of harmony led to the expressing what he called 'old harmony'. Overall, we found that Mondrian's early (1919-1923) theoretical standpoint toward his Neo-Plastic art was in many cases his crystalized, refined, aesthetic principles which he later in 1926 wrote them within six principles of Neo-Plasticism. Nevertheless, we also found and marked some degrees of immaturities, mainly in the execution of his 1919-1920 paintings, in Mondrian's early Neo-Plastic experimentations.

\section{Notes}

\footnotetext{
i Mondrian after 1914, called his paintings as 'composition'. Such term indeed is related to this fact that he arranged, composed, his abstracted elements of painting in opposition to attain the harmony, equilibrium.

ii In the first principle Mondrian stated: "[t]he plastic means must be the rectangular plane or prism in primary colors (red, blue, and yellow) and in noncolor (white, black, and gray). In architecture, empty space can be counted as noncolor, denaturalized material as color" (Mondrian, 1926, p. 209).

iii Second principle of Neo-Plasticism:
}

"Equivalence in the dimension and color of the plastic means is necessary. Although varying in dimension and color, the plastic means will nevertheless have an equal value. Generally, equilibrium implies a large area of noncolor or empty space opposed to a comparatively small area of color or material (Mondrian, 1926, p. 209)."

${ }^{\text {iv }}$ Mondrian in the third principle stated that: "Just as dual opposition is required in the plastic means, it is also required in the composition" (Mondrian, 1926, p. 209).

${ }^{\mathrm{v}}$ In the fourth principle of Neo-Plasticism we read: "[c]onstant equilibrium is achieved by the relationship of position and is expressed by the straight line (boundary of the pure plastic means) in its principal, perpendicular opposition." And in the fifth principle he said: "[e]quilibrium that neutralizes and annihilates the plastic means is achieved through the relationships of proportion in which they are placed and which create vital rhythm." (Mondrian, 1926, p. 209)

${ }^{v i}$ Sixth principle of Neo-Plasticism: "[n]aturalistic repetition, symmetry, must be excluded." (Mondrian, 1926, p. 209)

\section{List of Figures}

Figure 1: Mondrian, P. (ca. 1901-1908) Passion flower.

Figure 2: Mondrian, P. (1911). Evolution.

Figure 3: Mondrian, P. (1912). Still life with gingerpot 2.

Figure 4: Mondrian, P. (1913). Oval Composition (Trees).

Figures 5: Mondrian, P. (1915). Composition 10 in black and white.

Figure 6: Mondrian, P. (1916-1917). Composition in line, second state.

Figure 7: Mondrian, P. (1917). Composition III with Color Planes.

Figure 8: Mondrian, P. (1918). Composition with Colour Planes and Grey Lines.

Figure 9: Mondrian, P. (1919). Composition with grid 6: lozenge, composition with colours.

Figure 10: Mondrian, P. (1919). Checkerboard, Light Colors.

Figure 11: Mondrian, P. (1919). Composition with Red, Yellow, Blue and Black. 
Figure 12: Mondrian, P. (1920). No. VI / Composition No.IIa.

Figure 13: Mondrian, P. (1920). Composition with Red, Yellow and Blue.

Figure 14: Mondrian, P. (1920). Composition with Red Yellow, Blue and Black.

\section{References}

Blotkamp, C. (1994). Mondrian: The art of destruction. London, England: Reaktion Books Ltd Rathbonc Place. New York: Abrams.

Bois, Y. A. (1994). The iconoclast. In Y. A. Bois, J. Joosten, AZ Rudenstine, H. Jansen (Eds.), Piet Mondrian (1872-1944) Piet Mondrian, 1944, (pp. 313-372). Boston, New York, Toronto, and London: A Bulfinch Press Book.

Bois, Y. A., Joosten, J., Rudenstine, Z., \& Janssen, H. (1994). Piet Mondrian. Boston, New York, Toronto, London: A Bulfinch Press Book, Little, Brown and Company.

Holtzman, H. (1986). Piet Mondrian: The man and his work. In H. Holtzman, \& M.S. James (Eds. and trans.), The new art-the new life: the collected writings of Piet Mondrian (pp. 1-10). London: Thames and Hudson.

Holtzman, H., \& James, M. S. (1986). Chronology. In H. Holtzman, \& M.S. James (Eds. and trans.), The new art-the new life: the collected writings of Piet Mondrian (pp. xix-xxv). London: Thames and Hudson.

James, M.S. (1986). Piet Mondrian: Art and Theory to 1917. In H. Holtzman, \& M.S. James (Eds. and trans.), The new art-the new life: the collected writings of Piet Mondrian (pp. 11-19). London: Thames and Hudson.

Joosten, J. M., Mondrian, P., \& Welsh, R. P. (1998). Catalogue Raisonné of the Work of 1911-1944. Blaricum, Netherlands: $\mathrm{V}+\mathrm{K}$ Publishing Prestel.

Krauss, R., Bois, Y. A., Buchloh, B. H., \& Joselit, D. (2004). Art since 1900: modernism, antimodernism, postmodernism. London: Thames \& Hudson.

Mondrian, P. (1919-1920). Part I: The De Stijl Years: 1917-24: Natural Reality and Abstract Reality: A Trialogue (While Strolling from the Country to the City). In H. Holtzman, \& M.S. James (1986, Eds. and trans.), The new art-the new life: the collected writings of Piet Mondrian (pp. 82-123). London: Thames and Hudson.

(1920). Part I: The De Stijl Years: 1917-24: Neo-Plasticism: The General Principle of Plastic Equivalence. In H. Holtzman, \& M.S. James (1986, Eds. and trans.), The new art-the new life: the collected writings of Piet Mondrian (pp. 132-147). London: Thames and Hudson.

(1921). Part I: The De Stijl Years: 1917-24: The Manifestation of Neo-Plasticism in Music and the Italian Futurists' Bruiteurs. In H. Holtzman, \& M.S. James (1986, Eds. and trans.), The new art-the new life: the collected writings of Piet Mondrian (pp. 148-155). London: Thames and Hudson.

(1922). Part I: The De Stijl Years: 1917-24: Neo-Plasticism: Its Realization in Music and in Future Theater. In H. Holtzman, \& M.S. James (1986, Eds. and trans.), The new art-the new life: the collected writings of Piet Mondrian (pp. 156-163). London: Thames and Hudson.

. (1923a). Part I: The De Stijl Years: 1917-24: Is Painting Inferior to Architecture? In H. Holtzman, \& M.S. James (1986, Eds. and trans.), The new art-the new life: the collected writings of Piet Mondrian (pp. 173-174). London: Thames and Hudson.

(1923b). Part I: The De Stijl Years: 1917-24: Neo-Plasticism. In H. Holtzman, \& M.S. James (1986, Eds. and trans.), The new art-the new life: the collected writings of Piet Mondrian (pp. 175-177). London: Thames and Hudson. 
(1926). Part II: After De Stijl 1924-38: Home-Street-City (1926). In H. Holtzman, \& M.S. James (1986, Eds. and trans.), The new art-the new life: the collected writings of Piet Mondrian (pp. 205-212). London: Thames and Hudson.

Veen, L. A. (2017a). Piet Mondrian: The Complete Writings: Essays and Notes in Original Versions. Leiden, Netherlands: Primavera Pers.

Veen, L. A. (2017b). Piet Mondrian on the Principles of Neo-Plasticism. International Journal of Art and Art History, 5(2), 1-12. Doi: 10.1564o/ijaah.v5n2p1

Ali Fallahzadeh is currently (2019) in the process of graduating as a Ph.D. degree in the field of visual art from University of Malaya (UM) in Kuala Lumpur, Malaysia. The author in his Thesis examined the development of Dutch painter Piet Mondrian's Neo-Plastic theoretical ideas, focused on his six principles of Neo-Plasticism, by examining his 1917-1944 paintings and writings. He obtained his Bachelor Degree from Curtin University of Australia majoring in Arts \& Design. Then, he pursued his Master Degree in Visual Arts and Visual Communication Design in Eastern Mediterranean University (EMU) in North Cyprus. As an artist in the field of painting he experienced Watercolor and mixed media painting. The author has managed to hold some art exhibitions in Tehran and abroad. Moreover he practiced Iranian Calligraphy since 20 years ago. 